Väino Poikalainen

\title{
PALAEOLITHIC ART FROM THE DANUBE TO LAKE BAIKAL
}

This is a copy of the article from printed version of electronic journal

\section{Folklore Vol. 18\&19}

ISSN 1406-0957

Editors Mare Kõiva \& Andres Kuperjanov \& Väino Poikalainen \& Enn Ernits

Published by the Folk Belief and Media Group of ELM

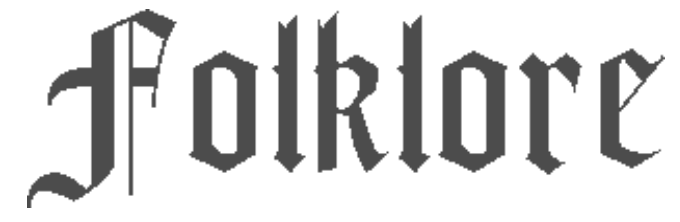

\section{Electronic Journal of Folklore}

Electronic version ISSN 1406-0949 is available from http://haldjas.folklore.eelfolklore

It's free but do give us credit when you cite! (C) Folk Belief and Media Group of ELM, Andres Kuperjanov

\section{Tartu 2001}




\section{PALAEOLITHIC ART FROM THE DANUBE TO LAKE BAIKAL}

\section{Väino Poikalainen}

The ancient history of humankind has been divided into three disproportionate periods based on material used for making tools: the Stone Age, the Bronze Age and the Iron Age. Bronze came into use only about 5000 years ago. The Stone Age extended over the longest period of prehistoric times that lasted for nearly two million years and it is therefore subdivided into the Palaeolithic (the early phase of the Stone Age), Mesolithic (the intermediate phase of the Stone Age) and Neolithic (the last phase of the Stone Age) periods. On the Estonian territory the Neolithic is estimated into the period 4,900-1,500 $\left(\mathrm{Cal}^{1}\right) \mathrm{BC}$ and the Mesolithic into the period 9,000-4,900 (Cal) BC (Kriiska 2001). The Palaeolithic Period extended to the end of the last Ice Age (200-10 millennia ago) and several subspecies of humans (homo) have left traces into these cultural strata. The modern man, or the sc. Cro-Magnon man (Homo sapiens sapiens) was preceded by the Neanderthal man (Homo sapiens neanderthalensis, 200-30 millennia ago), Homo erectus 1.6 millions 200,000 years ago and Homo habilis 2-1.5 million years ago (Lambert 1991).

Relying on the 130-150 millennia old sculls discovered most recently in South Africa and Ethiopia we can agree that Africa was the cradle of modern (Cro-Magnon) man. Corresponding anthropological finds from the Middle East date back to 90-100 millennia. Migration to Europe that was inhabited by the Neanderthals may therefore have taken place via the Middle East. Newcomers brought along a new archaeological culture (lifestyle, tools and methods) some 45-40 millennia ago to Central Europe, more than 36 millennia ago to Eastern Europe and 36-32 millennia ago to Western Europe (Anikovich 1999).

These changes took place in the last period of the Palaeolithic, also referred to as the Upper Palaeolithic. The end of the Palaeolithic period has in turn been subdivided by typical object finds into corresponding archaeological periods. In Western Europe these are called the Mousterian, Aurignacian, Gravettian, Solutrean and Magdale- 
nien periods. In Eastern Europe, however, a four-stage periodisation of the Upper Palaeolithic is used: the earlier phase - 50-38 millennia ago (Mousterian), the early phase - 37-27 millennia ago (Aurignacian), the intermediate phase 26-20 millennia ago (Gravettian) and the late phase 20-11 millennia ago (Solutrean and Magdalenien) (Sinitsyn 1999).

Development of material culture was rather conservative during the Palaeolithic. The most significant changes in living occurred only in the Mesolithic and Neolithic periods, when aggressive subsistence (hunting, fishing and foraging in the wild) was abandoned for the sake of cattle breeding and tillage. This break was preceded by intensive progress in intellectual culture, best examples of which are findings of prehistoric art originating from the end of the Pleistocene Epoch (and the Palaeolithic).

\section{GEOGRAPHICAL SITUATION AT THE END OF THE LAST ICE AGE. THEORIES OF ORIGIN OF FINNO-UGRIC PRIMAL TRIBES}

The last sc. Valdai (Würm) glaciating of the Pleistocene Epoch, which occurred about 70-10 thousand years ago, is often perceived as a constant process during which the gradual cooling of weather conditions prompted the maximum formation of glaciers about 20,000 years $(22,500 \mathrm{Cal})$ ago. This process was followed by a gradual retreat of ice sheet due to the warming of climate. In fact, several extensive and lengthy temperature fluctuations took place also before and after the glacial maximum. A relatively long interglacial period occurred 48-22 millennia ago (Figure 1). With the retreat of the ice sheet to the far North, human population settled even to the Pechora watershed (PSSSR 1984: 186).

Most discoveries of prehistoric art discussed in this article originate in the interglacial period preceding the glacial maximum, i.e. about 24-22 millennia ago; it may well be considered a period when the Palaeolithic plastic art in Central and Eastern Europe flourished. Major locations of this period lie within an arched belt stretching from the Upper Danube to the Upper Volga River. Art of this period, especially representation of humans, is relatively similar on the whole European territory. The distribution of stout female 


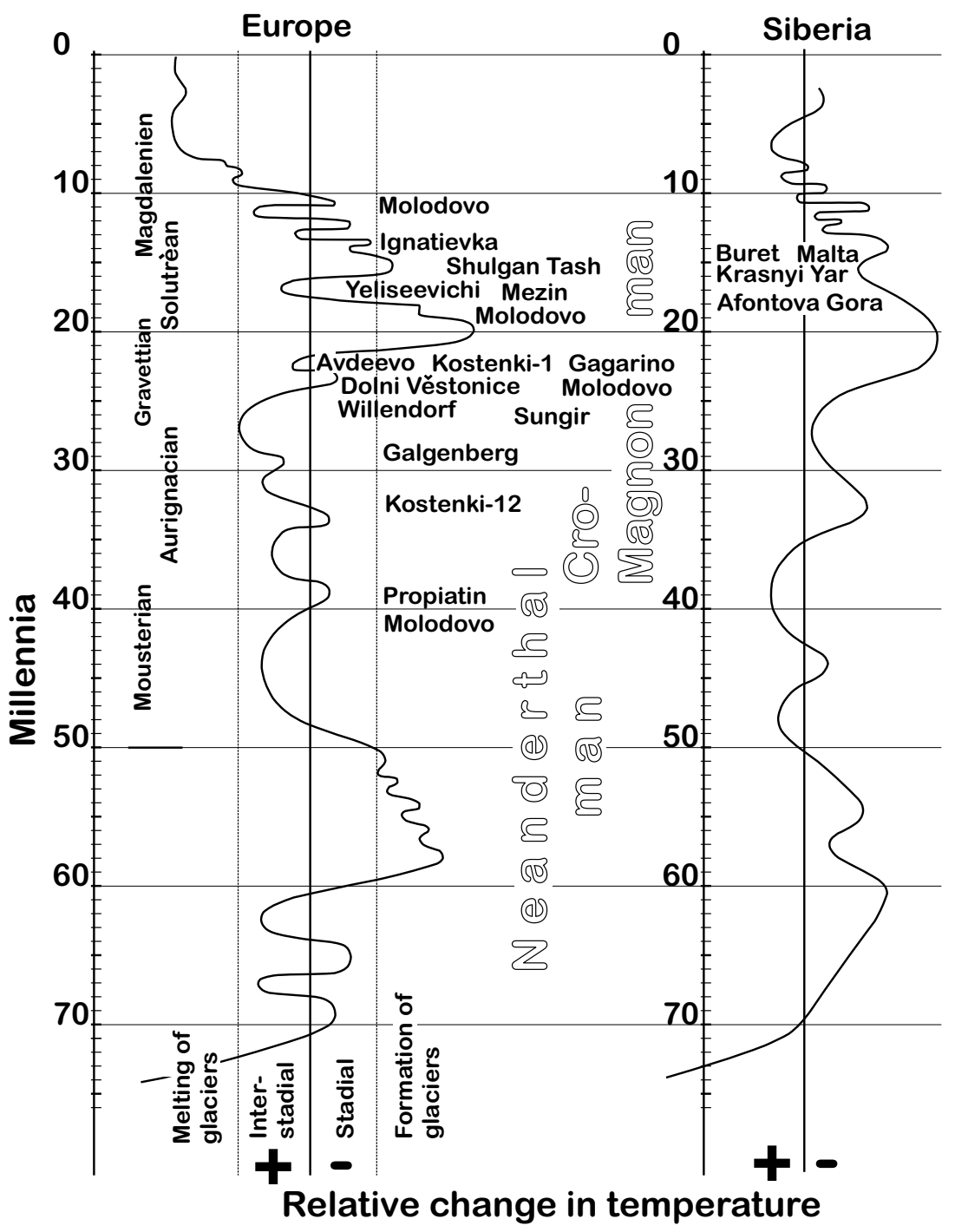

Figure 1. Temperature fluctuations during the Valdai (Würm) glaciating (PSSSR 1984: 31), periods and major sites of prehistoric art. 
figures from Western Europe to the East-Russian plateaux indicates the mobility of humans and the spread of similar beliefs in most of Europe. The Baltic Sea region may have been populated at that time as well, although there are no finds to prove this. The extant paleogeographical and archaeological material, scarce as it is, does not allow us to reconstruct the dynamics of human population of this period in a sufficiently convincing manner.

The new onset of continental glaciers repelled human population from the previously populated areas of the belt; some regions, however, remained very thinly populated. Glaciers moving southwards from Scandinavia and northwards from the Alps rendered the central part of Europe unsuitable for living, dividing human population in two. Contacts between West- and East-European population groups became complicated or even impossible for several millennia, exerting disintegrating influence on European languages, cultures, prehistoric art, etc.

Paleogeographical situation underwent considerable changes again at the end of the Upper Palaeolithic period. Retreating masses of ice formed new relief forms and the ground rapidly began to rise. Environmental conditions were determined also by huge remnant glaciers, vast inland bodies of water, formed from the melting ice, and powerful rivers running south- and westwards. Figure 2 demonstrates the position of the largest inland bodies of water in Europe and Siberia, riverbeds of the largest rivers and the shifting of continental ice sheet from the glacial maximum to the formation of the Baltic glacial lake about 10 millennia ago.

Settlements and discoveries of prehistoric artefacts originating in the Upper Palaeolithic Central and Eastern Europe (east of the Alps), the Urals and Siberia, have partly been determined by the contemporary aquatorium of inland waters. In Western Siberia no Palaeolithic finds have been discovered due to the fact that the area

Figure 2 (right). Paleogeographic situation in the late Pleistocene: $A-$ at the glacial maximum; $B$ - about 13 millennia ago; $C$ - about 10.5 millennia ago: 1 continental (a) and maritime (b) glaciers, 2 - open sea, 3-lakes, 4 - elongated elevations, 5 - courses of waterways, 6 - primeval valleys (Grosvald 1983: 9697) and major sites of prehistoric art before $(A)$ and after $(B, C)$ the glacial maximum. 

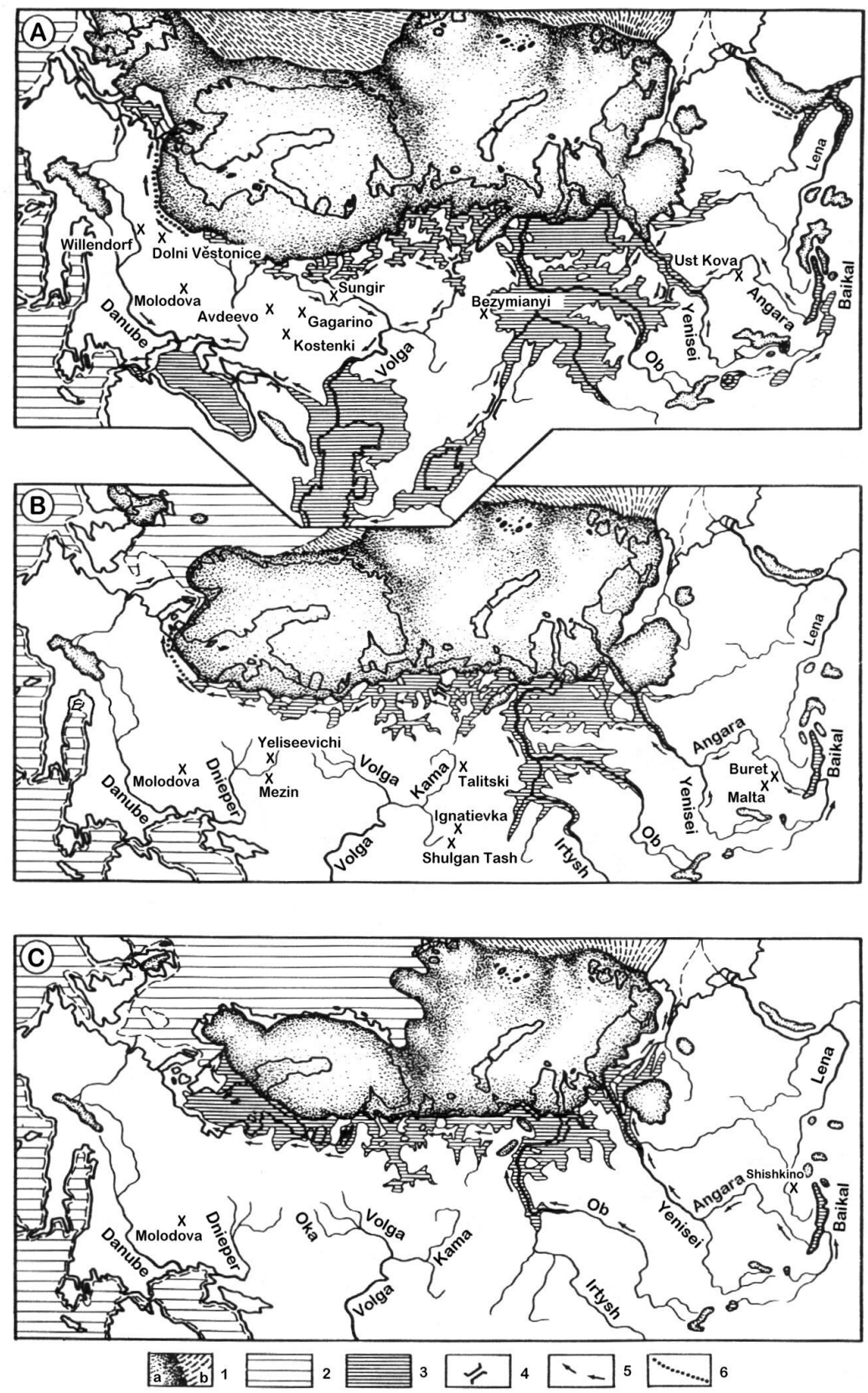
was under a vast glacial lake. Inland waters, no doubt, influenced the remigration of humans to the areas cleared of ice at the end of the glacial period. The predominantly east to west course of waters may have exerted influence on the moving of flora and fauna in the same direction.

Human population arrived back at the formerly settled areas millennia after the glacial maximum. For instance, new population settled in Molodova some 17 millennia ago, and in the KonstenkiBorshevo region more than 13 millennia ago (PSSSR 1984: 223225). Contacts between the population of Eastern and Western Europe were not re-established until the end of the glacial period, when human population settled on the southern coast of the Baltic Sea. Migration to the East-Polish and Lithuanian territories originated in the east and resulted in the emergence of the Swidry culture. Fosterers of the neighbouring Arensburg culture (who had settled to the West-Polish and North-German areas), however, were of western origin (Carpelan 2000). The Swidry culture developed into the Early Mesolithic Kunda culture, which in its turn spread further north and east and later gave rise to the Mesolithic VolgaOka culture (PSSSR 1984: 223-225).

Thus far there is no established connection between primary FinnoUgric tribes and specific Palaeolithic cultures. Still, we can be certain that during the last glacial maximum nearly all the presentday territories of the Finno-Ugric people were either covered with ice or were unsuitable for living. The later occupation of these areas by the ancestors of Uralic or Finno-Ugric language families could not have taken place before the areas were cleared of glaciers. Several theories have been postulated on the origin of settlements and the formation of the language family, the earlier of which are based on the sc. Finno-Ugric Uralic original home and the eastto-west migration proceeding from it. The hypothesis of the FinnoUgric origin of prehistoric pit-comb ceramic culture connected linguistic and archaeological material and laid the foundation for future allegation that the predecessors of Balto-Finnic tribes arrived from the Volga-Oka region at the Baltic coast during the last phase of the Stone Age, i.e. during the Neolithic. Relying on modern dating results it must have happened some 6,000 years ago, 4-5 millennia after the end of the Ice Age. 
Certain inconsistency between linguistic and archaeological material and the scarcity of objective information has prompted the scholars' increasing interest in the subject. According to the latest hypothesis the migration of Finno-Ugrians to their present territories originated mostly from south and occurred almost simultaneously with the retreat of glacial sheet (Julku 1997; Nuñes 1997). In this light we cannot speak about the Finno-Ugric Uralic original home, for in that case the Finno-Ugric and also the ancestors of Balto-Finnic tribes would have been living on their present-day territory since the end of the glacial period, and would have been, at the same time, the successors of the Swidry culture. Also, hypothesis concerning the Uralic original home allows us to associate FinnoUgrians with this culture, for one of the reasons for the emergence of the Mesolithic Volga-Oka culture is believed to be the eastward expansion of the Swidry culture. The Volga-Oka areas, in their turn, have transmitted cultural influences back to the Baltic coast, Finland and East-Karelia throughout the whole post-glacial prehistoric era in the Mesolithic Period, Neolithic Period and Bronze and Iron Age (Carpelan 2000).

It appears that most objects originating in the prime of Palaeolithic art cannot be associated with the ancestral tribes of a specific language family. Time lapse would be too long for that. But at the same time we can be certain that the upholders of Upper Palaeolithic cultures in Europe and possibly also in Siberia may partly have functioned as a substratum for primary Finno-Ugric tribes. Thus it would be wise to start by following the early development of prehistoric Finno-Ugric art on the area extending from Siberia to Central Europe.

\section{PREHISTORIC ART: ORIGIN, FORMS AND DEVELOPMENT}

The origin of prehistoric art has been associated with the period of the Upper Palaeolithic when the Cro-Magnon man settled in Europe and gradually outlived or repelled the Neanderthal man (see Figure 1). Only preliminary and primitive forms of prehistoric art are known from the earlier stage of the period. In his works A. D. Stoliar has thoroughly treated the preliminary phase of prehistoric 


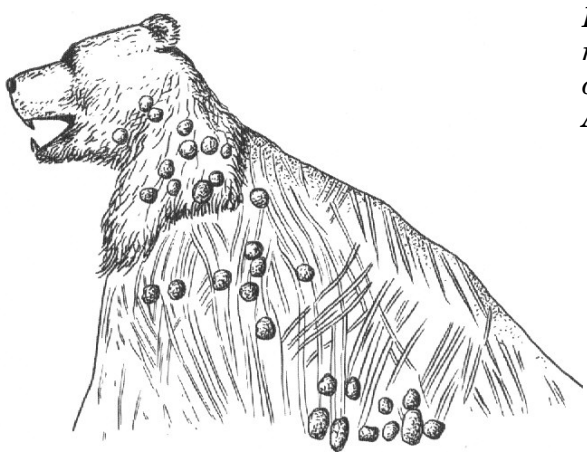

Figure 3. A natural model: the body made of stalagmite with the head of a cave bear.

After A. Stoliar (1985: 191).

art. According to his theory artistic creation was prompted by natural animal-like representations (Stoliar 1985). Adding certain elements these representations were formed into natural models and used for ritual purposes (Figure 3). The gradual elaboration of these natural models into animal-like representations led to man-made sculptures, figures and paintings.

The earliest figurative representations in Eastern Europe are bone engravings more than 40 thousand years old, dating back to the end of the Mousterian phase (Chernysh 1978; Sytnik 1983). During the following Aurignacian and Gravettian phases, that still preceded the glacial maximum, numerous miniature objects of plastic art were created. Cave art (paintings, engravings, sculptures and basreliefs) became widely spread during the Solutrean and Magdalenien phases after the glacial maximum. Locations with abundant finds of Palaeolithic cave art have been discovered in Franco-Cantabria (Southern France and Northern Spain). Until the discovery of cave paintings in the Urals in 1959, cave art was considered as something characteristic of Western Europe only (Riumin 1961).

So far no all-inclusive generalising theory has been postulated on the development of East-European and Asian prehistoric art. In Western countries and especially in France, however, the issue has been a subject of long-term discussion. Western authors argue that in Europe Palaeolithic art developed from primitive to the more elaborate (Figure 4). Prototypes of animal representations created during the Aurignacian phase are barely identifiable. Later, during 
the Gravettian and Solutrean phases, art became more expressive and detailed, where the fauna of glacial era are clearly recognisable. The prehistoric art of Western Europe reached its peak with polychromatic cave paintings and elaborate bone figurines and engravings of the Franco-Cantabria region during the Magdalenien phase, about 15 millennia ago.

The best examples of anthropomorphic and zoomorphic representations of East-European Palaeolithic art originate in the period preceding the glacial maximum, when plastic art in mammoth ivory and stone was fostered. After glacial maximum the representation

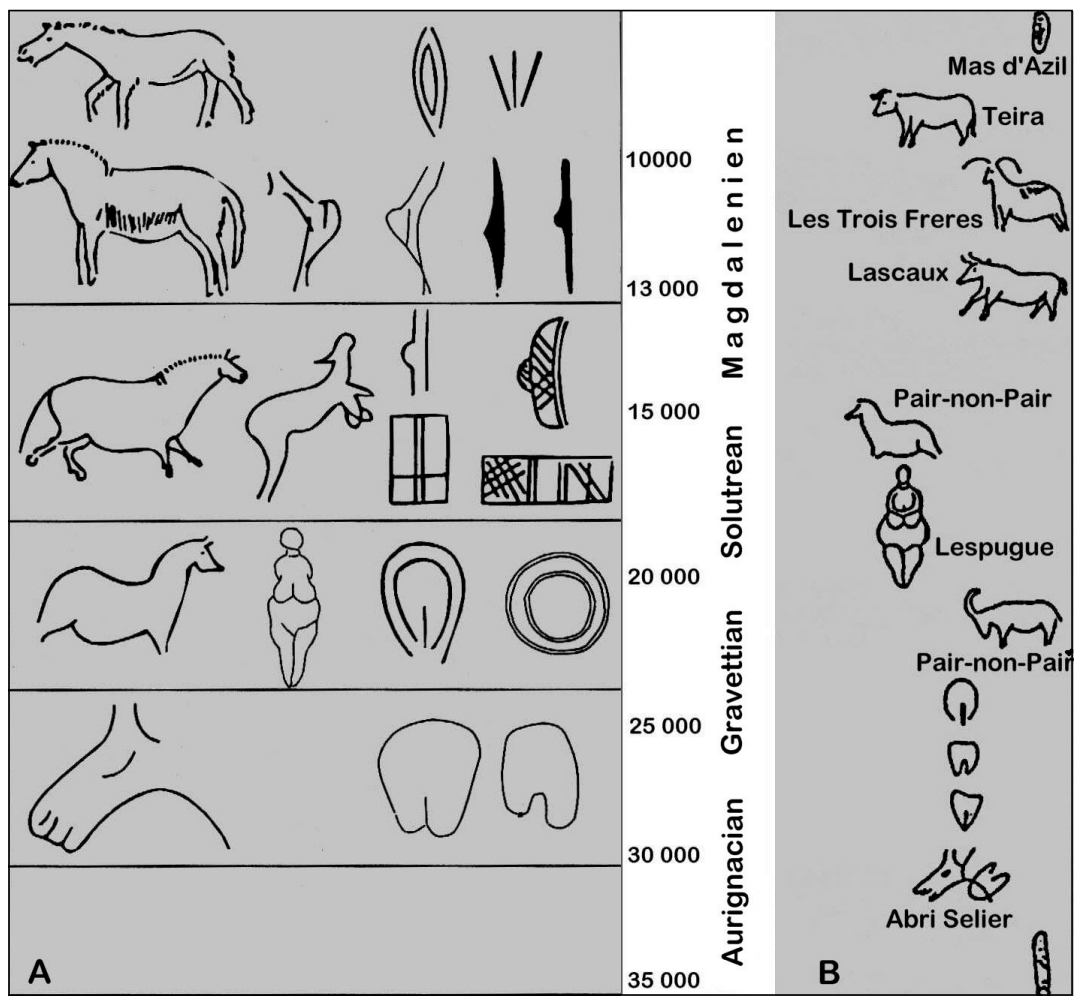

Figure 4. The genesis of Paleolithic art in Western Europe: A-after LeroiGourhan, B - after Lumley (Masson 1996: 52-53). 
of humans and animals became less common, while diverse ornament became widespread. Almost no anthropomorphic or zoomorphic representations from the last phase of the Upper Palaeolithic have been discovered, yet the number of known ornaments originating in the same period is quite large. Very few Mesolithic miniature sculptures comparable in artistic technique with Palaeolithic creation have been found as well. A unique exception here are the magnificent horn and bone artefacts from the Mesolithic Oleni Island burial ground of Lake Onega (Stolyar 2000).

MAJOR SITES OF PREHISTORIC ART

Central-Europe

The Ukraine

Central Russia

The Urals

Siberia 